\title{
1-methylnicotinamide and its structural analog 1,4-dimethylpyridine for the prevention of cancer metastasis
}

\author{
Agnieszka Blazejczyk', Marta Switalska', Stefan Chlopicki ${ }^{2,3}$, Andrzej Marcinek ${ }^{4}$, Jerzy Gebicki ${ }^{4}$, Marcin Nowak ${ }^{5}$, \\ Anna Nasulewicz-Goldeman ${ }^{1}$ and Joanna Wietrzyk ${ }^{1 *}$
}

\begin{abstract}
Background: 1-methylnicotinamide (1-MNA), an endogenous metabolite of nicotinamide, has recently gained interest due to its anti-inflammatory and anti-thrombotic activities linked to the COX-2/PGI 2 pathway. Given the previously reported anti-metastatic activity of prostacyclin $\left(\mathrm{PGI}_{2}\right)$, we aimed to assess the effects of 1-MNA and its structurally related analog, 1,4-dimethylpyridine (1,4-DMP), in the prevention of cancer metastasis.

Methods: All the studies on the anti-tumor and anti-metastatic activity of 1-MNA and 1,4-DMP were conducted using the model of murine mammary gland cancer (4T1) transplanted either orthotopically or intravenously into female BALB/c mouse. Additionally, the effect of the investigated molecules on cancer cell-induced angiogenesis was estimated using the matrigel plug assay utilizing 4T1 cells as a source of pro-angiogenic factors.

Results: Neither 1-MNA nor 1,4-DMP, when given in a monotherapy of metastatic cancer, influenced the growth of 4T1 primary tumors transplanted orthotopically; however, both compounds tended to inhibit 4T1 metastases formation in lungs of mice that were orthotopically or intravenously inoculated with 4T1 or 4T1-luc2-tdTomato cells, respectively. Additionally, while 1-MNA enhanced tumor vasculature formation and markedly increased $\mathrm{PG}_{2}$ generation, 1,4-DMP did not have such an effect. The anti-metastatic activity of 1-MNA and 1,4-DMP was further confirmed when both agents were applied with a cytostatic drug in a combined treatment of 4T1 murine mammary gland cancer what resulted in up to $80 \%$ diminution of lung metastases formation.

Conclusions: The results of the studies presented below indicate that 1-MNA and its structural analog 1,4-DMP prevent metastasis and might be beneficially implemented into the treatment of metastatic breast cancer to ensure a comprehensive strategy of metastasis control.
\end{abstract}

Keywords: 1-methylnicotinaimide chloride, 1,4-dimethylpyridinium chloride, Metastasis, Angiogenesis, Combined therapy, Breast cancer

\section{Background}

1-methylnicotinamide (1-MNA), an endogenous metabolite of nicotinamide (NA), is synthetized in the reaction of nicotinamide $\mathrm{N}$-methyltransferase (NNMT), an enzyme expressed predominantly in the liver, where it plays a pivotal role in the N-methylation of NA and possibly other pyridine compounds [1]. However, NNMT expression has also been reported in a number of other types of cells and

\footnotetext{
*Correspondence: wietrzyk@iitd.pan.wroc.pl

'Hirszfeld Institute of Immunology and Experimental Therapy, Polish

Academy of Sciences, Weigla 12, 53-114 Wroclaw, Poland

Full list of author information is available at the end of the article
}

organs, including rapidly proliferating cancer cells [2-4] or the brains of the patients suffering from Parkinson's disease [5]. For decades it has been nicotinamide, a substrate for the NNMT reaction that has attracted attention as a possible therapeutic agent endowed with pharmacological activities [6-9]. Meanwhile, 1-MNA has been considered an inactive metabolite [10]. Only recently has some evidence for the possible therapeutic application of 1-MNA emerged. The first signals for its pharmacological potential date back to 2003, when Gebicki et al. described its anti-inflammatory activity in 
skin disorders such as acne or contact dermatitis [11], which was further confirmed in an additional study involving patients with rosacea [12]. In turn, studies by Chlopicki et al. demonstrated that the mechanisms of action of 1-MNA involve the activation of $\mathrm{PGI}_{2}$ release driven by cyclooxygenase 2 (COX-2) [13]. $\mathrm{PGI}_{2}$ releasing capacity of 1-MNA was later shown to afford not only anti-thrombotic [13] but also fibrinolytic [14], antiinflammatory [11, 15] and gastroprotective [16] effects. Interestingly, 1-MNA did not directly either affect the activity of leucocytes $[15,17]$ or release $\mathrm{PGI}_{2}$ in the perfused rat hindquarters model [18]. Still, 1-MNA, due to its $\mathrm{PGI}_{2}$ releasing capacity, might serve as a hepatoprotective agent that protects against concanavalin A induced liver injury [19] through the downregulation of interleukin-4 (IL-4) and tumor necrosis factor- $\alpha$ signalization (TNF- $\alpha$ ) [20]. In addition to its anti-platelet, anti-thrombotic and antiinflammatory activities, 1-MNA has also been shown to restore endothelial function in diabetic hypertriglycemic rats [21], as well as to improve endothelial function in humans [22].

Given the reports demonstrating that $\mathrm{PGI}_{2}$ displays anti-metastatic activity $[23,24]$, and the $\mathrm{PGI}_{2}$ releasing activity of 1-MNA [13], the potential application of exogenous 1-MNA to prevent metastatic cancer seems to be justified. However, currently only limited reports on the in vivo anti-cancer activity of 1-MNA are available, including the daily use of 1-MNA in mice bearing murine leukemia L1210 that resulted in about a $50 \%$ lifespan increase [25] or the disclosure of the use of 1MNA in the prevention of experimental metastases formation [26].

In his patent application Gebicki et al. [26] discloses also the use of the 1-MNA's analog, 1,4-dimethylpyridine (1,4DMP), another pyridine compound naturally occurring in roasted coffee seeds. 1,4-DMP is believed to be at least partially responsible for health-beneficial effects of coffee and as such has been shown to inhibit thrombus formation in vivo. As it has been observed for 1-MNA, the antihrombotic activity of 1,4-DMP depends on the prostacyclin-related mechanisms [27]. What is more, results of our preliminary studies have shown that 1,4DMP inhibits metastases formation in the model of spontaneously metastasizing murine mammary gland cancer (4T1) [28]. Nevertheless, none of the mentioned reports provide any detailed evidence of the impact revealed by 1 -MNA or 1,4-DMP on the growth and metastasis of solid tumors.

Metastasis is a complex process comprising several discrete steps that result in the formation of secondary lesions localized at a distance from the primary tumor. Due to their characteristics, metastases often fail to respond to standard chemotherapy and appear to be inaccessible for irradiation or surgical treatment. Therefore, their development usually leads to a dramatic deterioration in survival prognosis, which, in turn, justifies the common urge for modern therapeutic regimes enabling the control of metastatic dissemination. Since it is undeniable that successful metastasis relies on the complex interactions between cancer cells and host body tissues, one can expect that selective interference with such an interaction would reduce metastatic potential. The phenomena occurring in a host body tissues that have been suggested to beneficially influence cancer progression comprise, for example, tumor vessel formation, tumor immune editing and also tumor cell induced platelet aggregation (TCIPA). The latter seems to be of particular interest, as it not only promotes cancer metastasis but also increases patients mortality due to cardiovascular incidents [29]. Nevertheless, platelets undoubtedly contribute to metastasis efficiency as they physically shield migrating cancer cells in the bloodstream, facilitate immune evasion [30,31], and promote cancer cell adhesion to the endothelium of the microvasculature in a target tissue [32,33]. Thus, platelets appear to be a promising alternative target for metastasis prevention. Inhibition of metastases development by anti-platelet pharmacotherapy has been previously studied, and to date multiple data on the antimetastatic potential of anti-platelet agents have been reported [34-37]. $\mathrm{PGI}_{2}$ is the most potent endogenous anti-platelet agent that, together with its analogs, has been shown to prevent cancer metastasis [23, 38-42]; however, the unfavorable short lifetime of the parent molecule and the hypotensive action of its potent analogs limit their application.

Given the $\mathrm{PGI}_{2}$-related mechanism of action of 1-MNA and 1,4-DMP, we decided to investigate whether these compounds may possess any significant anti-cancer activity in the model of highly metastatic murine mammary gland cancer (4T1). The secondary aim of the presented study was to determine the possibility to utilize both of the compounds in a therapeutic regimen additionally comprising cyclophosphamide.

\section{Methods \\ Compounds}

1-methylnicotinamide (1-MNA) and 1,4-dimethylpyridinium (1,4-DMP) were used in the form of chlorides provided by the Lodz University of Technology. Prior to use, pyridinium salts were diluted in drinking water such that mice received $100 \mathrm{mg} / \mathrm{kg} /$ day of the drug. Cyclophosphamide (Endoxan) was purchased from Baxter Oncology GmbH, (Germany). All the drugs were administrated according to the dosing and administration schedules provided in Table 1 and corresponding graphs below. 
Table 1 Drugs, doses and therapeutic regimens applied in the presented studies

\begin{tabular}{|c|c|c|c|c|}
\hline Experimental model & Drug & $\begin{array}{l}\text { Route of } \\
\text { administration }\end{array}$ & Dose & Treatment regimen \\
\hline \multirow[t]{2}{*}{ Experimental metastasis (Fig. 1) } & 1-MNA & \multirow{2}{*}{$\begin{array}{l}\text { Per os in } \\
\text { drinking water }\end{array}$} & \multirow[t]{2}{*}{$100 \mathrm{mg} / \mathrm{kg} /$ day } & \multirow{2}{*}{$\begin{array}{l}\text { Treatment initiated } 7 \text { days prior cancer transplantation } \\
\text { and continued to the end of the experiment }\end{array}$} \\
\hline & 1,4-DMP & & & \\
\hline \multirow{2}{*}{$\begin{array}{l}\text { Spontaneous metastasis (single } \\
\text { drug treatment) (Fig. 2) }\end{array}$} & 1-MNA & \multirow{2}{*}{$\begin{array}{l}\text { Per os in } \\
\text { drinking water }\end{array}$} & \multirow[t]{2}{*}{100 mg/kg/day } & \multirow{2}{*}{$\begin{array}{l}\text { Continuously from the } 7 \text { th day of the experiment to } \\
\text { the end of the experiment }\end{array}$} \\
\hline & 1,4-DMP & & & \\
\hline \multirow[t]{3}{*}{ Matrigel plugs (Fig. 3) } & 1-MNA & \multirow{2}{*}{$\begin{array}{l}\text { Per os in } \\
\text { drinking water }\end{array}$} & \multirow[t]{2}{*}{100 mg/kg/day } & \multirow{2}{*}{$\begin{array}{l}\text { Continuously starting from the day of matrigel plugs } \\
\text { transplantation }\end{array}$} \\
\hline & 1,4-DMP & & & \\
\hline & Cyclophosphamide & intraperitoneally & $25 \mathrm{mg} / \mathrm{kg} /$ day & On days $0,3,5$ \\
\hline \multirow{3}{*}{$\begin{array}{l}\text { Spontaneous metastasis (combined } \\
\text { treatment) (Fig. } 4 \text { and 5) }\end{array}$} & 1-MNA & \multirow{2}{*}{$\begin{array}{l}\text { Per os in } \\
\text { drinking water }\end{array}$} & \multirow[t]{2}{*}{100 mg/kg/day } & \multirow{2}{*}{$\begin{array}{l}\text { Continuously from the 1st day of the experiment to the } \\
\text { end of the experiment }\end{array}$} \\
\hline & 1,4-DMP & & & \\
\hline & Cyclophosphamide & Intraperitoneally & $25 \mathrm{mg} / \mathrm{kg} / \mathrm{day}$ & From the 7 th day of the experiment, 3 times each week \\
\hline
\end{tabular}

\section{Mice}

7/8-week-old BALB/c female mice were purchased from the Center of Experimental Medicine, Medical University of Bialystok, Poland. 7/8-week-old BALB/c Nude female mice were provided by Charles Rivers Laboratories (Germany). All experiments were performed according to the Interdisciplinary Principles and Guidelines for the Use of Animals in Research, Marketing and Education issued by the New York Academy of Sciences' Ad Hoc Committee on Animal Research and were approved by the 1st Local Committee for Experiments with the Use of Laboratory Animals, Wroclaw, Poland (Table 2).

\section{Cell culture and transplantation}

The mouse mammary adenocarcinoma 4T1 cells were obtained from the American Type Culture Collection (ATCC, USA). Cells were cultured in RPMI 1640 (IIET, Poland) with Opti-MEM ${ }^{\bullet}$ (Life Technologies, USA) $(1: 1 \mathrm{v} / \mathrm{v})$ medium with $5 \%$ fetal bovine serum (HyClone, Thermo Fisher Scientific Inc. UK), supplemented with $4.5 \mathrm{~g} / \mathrm{L}$ glucose, $2 \mathrm{mM}$ glutamine, $1.0 \mathrm{mM}$ sodium pyruvate (all from Sigma-Aldrich, Germany) and antibiotics (penicillin and streptomycin - Polfa Tarchomin, Poland). The mouse mammary adenocarcinoma 4T1luc2-tdTomato cell line stably expressing the firefly

Table 2 Strains and number of mice used in the experiments

\begin{tabular}{llll}
\hline Experimental model & $\begin{array}{l}\text { Mouse } \\
\text { strain }\end{array}$ & $\begin{array}{l}\text { No. of mice/ } \\
\text { group }\end{array}$ & $\begin{array}{l}\text { Total No. of } \\
\text { used mice }\end{array}$ \\
\hline $\begin{array}{l}\text { Experimental metastasis } \\
\text { (Fig. 1) }\end{array}$ & $\begin{array}{l}\text { BALB/C } \\
\text { Nude }\end{array}$ & 7 & 21 \\
$\begin{array}{l}\text { Spontaneous metastasis } \\
\text { (single drug treatment) }\end{array}$ & BALB/C & 10 & 30 \\
$\begin{array}{l}\text { (Fig. 2) } \\
\text { Matrigel plugs (Fig. 3) }\end{array}$ & 9 & 36 \\
$\begin{array}{l}\text { Spontaneous metastasis } \\
\text { (combined treatment) }\end{array}$ & 10 & 50 \\
(Figs. 4 and 5) & & \\
\hline
\end{tabular}

luciferase gene and tdTomato fluorescent protein was obtained from Caliper Life Sciences Inc. (USA). Cells were cultured in RPMI $1640+$ Gluta-MAX ${ }^{\mathrm{m}}$ medium (Life Technologies, USA) supplemented with $10 \%$ fetal bovine serum (Sigma-Aldrich, Germany) and antibiotics (penicillin and streptomycin - Polfa Tarchomin, Poland). Both cell line cultures were maintained at $37{ }^{\circ} \mathrm{C}$ in a humidified atmosphere with $5 \% \mathrm{CO}_{2}$.

Irrespective of the tumor model applied prior to the transplantations, all cells were trypsinized (IIET, Poland), centrifuged (200 g, $\left.4{ }^{\circ} \mathrm{C}, 5 \mathrm{~min}\right)$ and counted. For the model of spontaneous metastasis, 4T1 cells were resuspended in Hank's Balanced Salt Solution (HBSS; IIET, Poland) such that a suspension of $3 \times 10^{5} 4 \mathrm{~T} 1$ cells in $0.05 \mathrm{ml}$ of HBSS was inoculated into the mammary gland of female BALB/c mice. For the model of experimental metastasis, 4T1-luc2-tdTomato cells were resuspended in HBSS such that a suspension of $3 \times 10^{5}$ 4T1-luc2tdTomato cells in $0.1 \mathrm{ml} \mathrm{HBSS}$ was injected into the tail vein of each female BALB/c Nude mice. For the model of matrigel plugs, 4T1 cells were resuspended in the mixture of matrigel (BD Matrigel Basement Matrix High Concentration, Becton, Dickinson and Company, USA) and HBSS (5:1) such that $1 \times 10^{4}$ cells suspended in $0.3 \mathrm{ml}$ mixture was injected subcutaneously on the right flank of each female BALB/c mice.

\section{Estimation of the anti-tumor activity}

When tumors became palpable, their maximum length and width were measured 3 times a week, and the tumor volume was calculated according to the following formula:

$$
T V=\frac{1}{2} \times a^{2} \times b
$$

Where TV is the tumor volume, $\mathrm{a}$ is the shorter diameter and $\mathrm{b}$ is the longer diameter. To compare tumor growth inhibiting activity between the experimental groups, tumor 
growth inhibition values were estimated using the following formula:

$$
T G I=100-\frac{T V_{N}}{T V_{C}} \times 100
$$

Where TGI is the tumor growth inhibition value, $\mathrm{TV}_{\mathrm{N}}$ is the mean tumor volume calculated for the studied experimental group and $\mathrm{TV}_{\mathrm{C}}$ is the mean tumor volume calculated for the control group of animals.

\section{Evaluation of the anti-metastatic effect}

To determine the anti-metastatic activity of the compounds, the lungs of tumor bearing mice were excised, weighed and transferred into $5 \%$ solution of buffered formalin. After tissue fixation, metastatic foci were counted visually. In the model of experimental metastasis, in vivo visualizations of the metastatic foci localized in lungs were performed every third day, starting from the tenth day of the experiment using an In vivo MS FX PRO system (Carestream Health INC., USA). In brief, about ten minutes before imaging, D-luciferine potassium salt (Synchem INC., Germany) was administered to each mouse intraperitoneally at the dose of $150 \mathrm{mg} / \mathrm{kg}$. Then, animals were anesthetized with a 3-5\% (v/v) mixture of isoflurane (Forane, Abbott Laboratories, USA) in synthetic air $(200 \mathrm{ml} / \mathrm{min})$. Anesthesia was maintained by means of individual masks providing a $1.5-2 \%(\mathrm{v} / \mathrm{v})$ mixture of isoflurane and synthetic air. Visualization was carried out using the following settings: for X-Ray $t=2 \mathrm{~min}, \mathrm{f}$-stop $=5.57$, FOV $=198.6$; for luminescence capture $\mathrm{t}=3 \mathrm{~min}$, binning $2 \times 2$, f-stop $=$ 5.57, FOV $=198.6$. Images were analyzed with Carestream MI SE software (Carestream Health INC., USA). The intensity of the luminescent signal is presented as the sum intensity of the region of interest and expressed in arbitrary units [a.u.].

\section{Evaluation of tumor angiogenesis}

The influence of 1-MNA and 1,4-DMP on tumor angiogenesis was evaluated in the model of spontaneously metastasizing $4 \mathrm{~T} 1$ tumors and confirmed in the model of matrigel plugs. Analyzes were performed by means of ultrasound imaging of tumor perfusion or immunohistochemistry staining of platelet endothelial cell adhesion molecules (PECAM-1; CD31) in the matrigel matrix, respectively. For the ultrasound imaging, the MicroMarker $^{\mathrm{rm}}$ Contrast Agent (VisualSonics, Canada) was prepared according to the manufacturer's instructions. Animals were anesthetized with the 3-5 \% (v/v) mixture of isoflurane (Forane, Abbott Laboratories, USA) in synthetic air $(200 \mathrm{ml} / \mathrm{min})$ and placed on an animal handling station equipped with an individual mask providing a $1.5-2 \%(\mathrm{v} / \mathrm{v})$ mixture of isoflurane and synthetic air. The position of the handling station was adjusted so that the central section of the tumor was being visualized and the contrast agent was injected into the tail vein of the animal. The signal of the contrast marker accumulating in the tumor mass was recorded using a probe of 13-24 Mhz frequency (MS250, VisualSonics, Canada). Next, the wash-in rate was calculated using Vevo LAB 1.7.1. Software (VisualSonics, Ontario, Canada).

Immunohistochemistry was performed in matrigel plugs (isolated from mice on the 7th day after the transplantation) which were fixed in buffered formalin and then cut into 4- $\mu \mathrm{m}$-thick sections that were subsequently dewaxed with xylene and rehydrated in a gradient of ethanol. For antigen retrieval, sections were heated in a water bath at $96{ }^{\circ} \mathrm{C}$ for 20 min with EnVision ${ }^{\text {Tu }}$ FLEX Target Retrieval Solution, High $\mathrm{pH}$ (Dako ${ }^{\circ}$, Carpinteria, USA). Endogenous peroxidase activity was quenched in EnVision $^{\text {TM }}$ FLEX Peroxidase-Blocking Reagent for $5 \mathrm{~min}$. Thereafter, sections were incubated with primary antibody against PECAM-1 (diluted in 1:50 ratio). Subsequently, sections were washed in EnVision ${ }^{\text {Tx }}$ FLEX Wash Buffer and detection system EnVision ${ }^{\mathrm{Tm}}$ FLEX/HR SM802 was added for $30 \mathrm{~min}$ at room temperature. The reaction was developed using 3,3-diaminebezidine tetrahydrochloride solution (DAB, EnVision ${ }^{\mathrm{Tm}}$ FLEX DAB+ Chromogen $\left(\mathrm{DAKO}^{\circ}\right.$, Carpinteria, USA). Finally, sections were washed in distilled water and nuclei were counterstained in hematoxylin, preparations were dehydrated in an alcohol gradient and coverslip mounted. Mean vessel density was evaluated by counting PECAM-1-positive vessels in 5 different fields of view at $200 \times$ magnitude.

\section{Platelet activation status}

Blood samples from the experimental animals were collected on the last day of the experiments. Samples were collected into tubes containing $0.05 \mathrm{ml}$ of $5 \%$ ethylenediaminetetraacetic acid (EDTA) solution (Sigma-Aldrich, Germany). Then, blood plasma was obtained by centrifugation $\left(2000 \mathrm{~g}, 15 \mathrm{~min}, 4{ }^{\circ} \mathrm{C}\right.$ ) and stored at $-80{ }^{\circ} \mathrm{C}$ until further analyzed. Prostacyclin generation in the treated mice was determined by the quantification of plasma 6 keto-prostaglandin F1 $\alpha$ (6-keto-PGF1 $\alpha$ ) levels. Platelet activation status was estimated on the basis of thromboxane $\mathrm{B}_{2}\left(\mathrm{TXB}_{2}\right)$, von Willebrand factor (vWF) and soluble P-selectin plasma concentrations. All analyzes were conducted using commercial ELISA kits available from Cusabio Biotech CO., Ltd (Wuhan, China), according to the manufacturer's instructions.

\section{E-cadherin/ $\mathrm{N}$-cadherin expression in tumor tissue}

Protein expression in 4T1 tumor tissue was analyzed according to the standard Western blot procedure [43]. In brief, samples of tumor tissue collected and immediately frozen on the last day of the experiments were 
homogenized in RIPA Buffer (Sigma-Aldrich, Germany) using a FastPrep ${ }^{\circ}$-24 MP Bio device (Mp Biomedicals LLC., USA) with the following settings: CP $24 \times 2,6 \mathrm{~m} / \mathrm{s}$, $40 \mathrm{~s}$. Protein content in all samples was analyzed using a Bio-Rad Protein Assay (Bio-Rad Laboratories Inc., USA) according to the manufacturer's protocol. Samples containing $100 \mu \mathrm{g}$ of protein were separated on the pre-cast 4-20\% gradient gels (Bio-Rad Laboratories, Inc., USA) and transferred onto $0.45 \mu \mathrm{m}$ polyvinylidene fluoride (PVDF) membranes (Merck Millipore, USA). Next the membranes were probed with primary rabbit polyclonal anti-E-cadherin, anti-N-cadherin antibodies (1:1000, both from Proteintech Group, USA) or rabbit anti- $\beta$-actin (1:1000, Sigma-Aldrich, Germany) antibody. Finally, analyzed proteins were detected with secondary anti-rabbit antibody conjugated with alkaline phosphatase (ECF Western Blotting Reagent Pack, GE Healthcare, Great Britain) and the signal was developed according to manufacturer's instruction. Blots were visualized in Image Station 4000MM (Carestream Healthcare Inc., USA) and analyzed with ImageJ Software, as follows. The total E-cadherin cellular content comprising mature and unprocessed E-cadherin (with a molecular weight of approximately 100 and $130 \mathrm{kDa}$, respectively) was calculated. Then, E-cadherin and $\mathrm{N}$-cadherin contents were normalized to $\beta$-actin. Finally, E-cadherin to $\mathrm{N}$ cadherin ratios in individual samples were calculated and presented as median values.

\section{Systemic toxicity of the anti-cancer treatment}

The toxicity of the proposed anti-cancer treatment strategy and its influence on the overall health condition was estimated on the basis of body weight changes as well as morphological blood analyzes. The body weight of experimental animals was measured three times each week throughout the course of all studies. Body weight changes were calculated using the following formula:

$$
\% B W=\frac{W_{N}}{W_{0}} \times 100-100
$$

where: $\mathrm{W}_{\mathrm{N}}$ is the mean body weight of the animals on each successive day of the experiment; $W_{0}$ is the mean body weight of the animals calculated for day 0 of the experiment.

\section{Statistical analysis}

Data normality was estimated using the Shapiro-Wilk test with a predetermined $p<0.05$ value. The TukeyKramer multiple comparisons test for parametric data or the Kruskal Walis Test for non-parametric data were applied; $p$ values lower than 0.05 were considered significant. All calculations were performed using STATISTICA
10 (StatSoft Inc., USA) or GraphPad Prism 6 (GraphPad Software, Inc., USA) software.

Unless stated otherwise all data presented on graphs correspond to median values $\pm \mathrm{min} / \mathrm{max}$.

\section{Results \\ Anti-cancer activity of 1-MNA and 1,4-DMP in a single drug therapy}

To assess the potential ability of 1-MNA and 1,4-DMP to inhibit metastases formation 4T1-luc2-tdTomato cells were intravenously inoculated into female BALB/c Nude mice that were pretreated with 1-MNA or 1,4-DMP for 7 days before transplantation. In vivo visualization of the metastatic lesions in lungs revealed that administration of either 1-MNA or 1,4-DMP resulted in delayed onset of metastatic lesion formation in mice (on the 10th day of the experiment metastatic lesions were observed in 3 out of 7 treated animals, whereas 5 out of 7 animals were diagnosed with lung metastases in the control group; Fig. 1b) and retarded metastases growth as estimated by means of intravital imaging of the lesions localized in lungs (Fig. 1a). When compared to the control group of mice the survival rate among the 1-MNA or 1,4-DMPtreated animals was increased by approximately $30 \%$ on the last 22nd day of the experiment (in both of the groups 3 out of 7 animals survived until 22nd day of the experiment' while there were no surviving animals in the control group, Fig. 1c). Prolonged treatment with 1-MNA and 1,4-DMP did not induce any side effects as during the whole experiment no symptoms of treatment related toxicity was observed (Additional file 1: Figure S1).

Since both 1-MNA and 1,4-DMP, while being well tolerated and non-toxic, featured anti-metastatic properties, their anti-cancer activity was further evaluated in the model of spontaneously metastasizing 4T1 murine mammary gland cancer. As presented in Fig. 2a, when administrated from the 7th day of the experiment, none of the tested compounds influenced the growth kinetics of 4T1 primary tumors transplanted into syngeneic BALB/c mice. Despite the lack of the anti-tumor activity, 1,4-DMP inhibited the formation of lung metastases by about $40 \%$ in comparison to the control (17 vs. 29 median number of lung metastases, respectively, Fig. 2b). Additionally, the influence of both 1-MNA and 1,4-DMP on tumor angiogenesis was estimated. The results of the intravital ultrasound imaging of blood flow in tumor tissue reflected in wash-in rate parameter values indicated that 1,4-DMP did not influence tumor blood vessel formation (Fig. 2c, 2d(III)). 1-MNA, in turn, did not reveal any marked anti-metastatic activity (Fig. 2b); however, surprisingly it increased the value of the wash-in rate parameter by $40 \%$ when compared to the control group of animals (the median value of wash-in rate expressed in arbitrary 

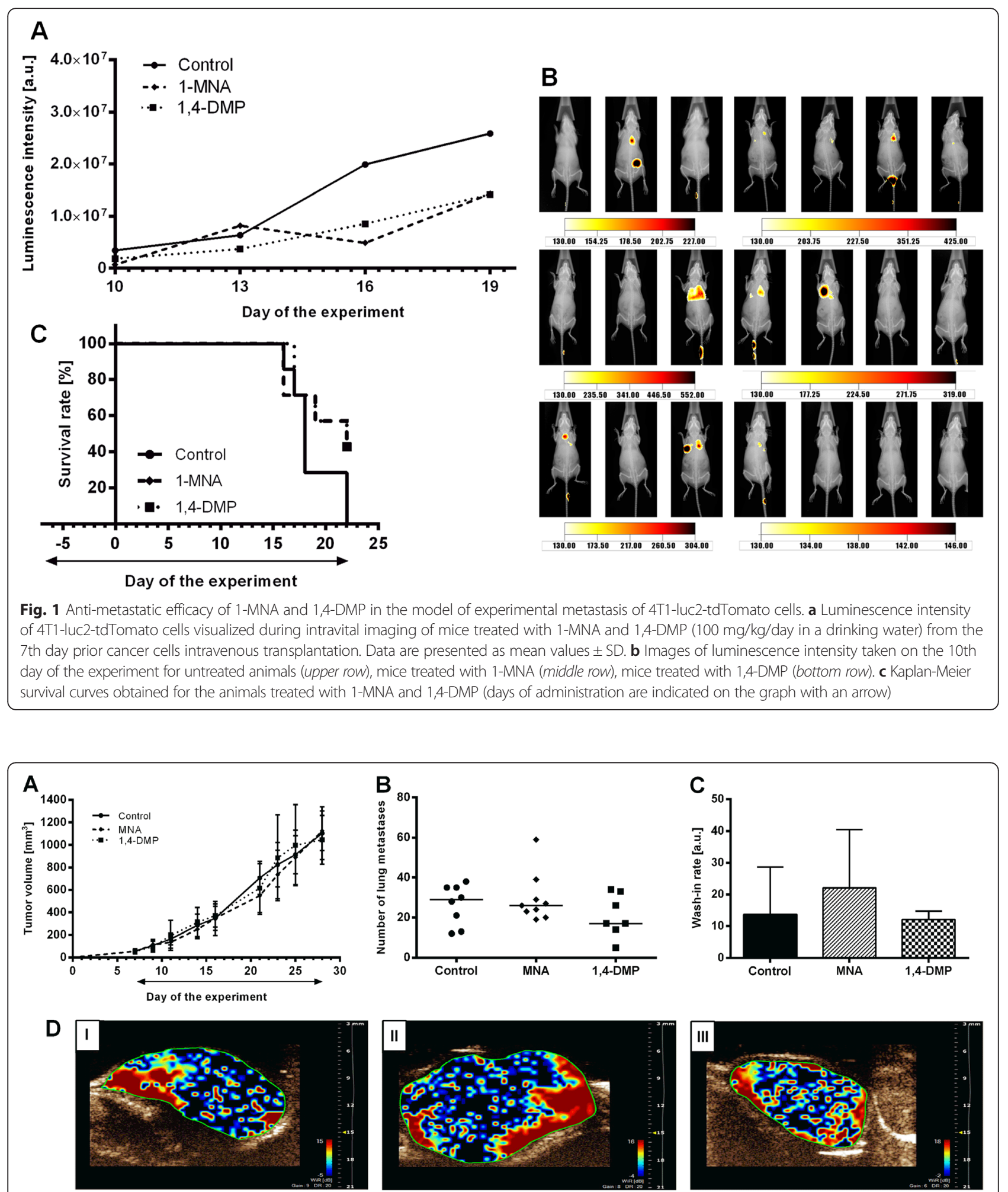

Fig. 2 The influence of 1-MNA and 1,4-DMP on the growth, angiogenesis and metastasis of 4T1 tumors. a Tumor growth kinetics in mice treated with 1-MNA or 1,4-DMP given at the dose of $100 \mathrm{mg} / \mathrm{kg} /$ day in drinking water from the 7 th day of the experiment (administration period is marked on the graph with an arrow). Data are presented as mean values \pm SD. b Median number of lung metastases in BALB/C mice bearing $4 T 1$ tumors. Data are presented as raw values with medians. c Wash-in-rate values estimated by the ultrasound imaging of 4T1 tumor blood perfusion performed on the 25 th day of the experiment. Data are presented as median values $\pm \mathrm{min} / \mathrm{max}$. $\mathbf{d}$ Representative images of tumor perfusion taken for: (I) control group, (II) mice treated with 1-MNA and (III) mice treated with 1,4-DMP 
units [a.u.] was estimated to be 22.1 vs. 13.6, respectively, Fig. 2c, 2d (II)).

To confirm the pro-angiogenic activity of 1-MNA observed in the model of the spontaneous metastasis of 4T1 tumors, the effect of 1-MNA and 1,4-DMP on tumor angiogenesis was additionally analyzed in the model of 4T1 cancer-cell induced angiogenesis utilizing matrigel plugs. Cyclophosphamide given in a metronomic regime served in this study as a control anti-angiogenic treatment and proved its efficacy, resulting in about a $30 \%$ lower mean microvessel density (Fig. $3 \mathrm{a}$ and $3 \mathrm{~b}(\mathrm{II})$ ) when compared to the control group (Fig. 3a and 3b(I)) (MVD of 3.5 vs. MVD of 5.1, respectively). Interestingly, 1-MNA tended to enhance blood vessel formation, as shown by the median microvessel density in sections obtained on the 7th day of the experiment (MVD of 7.1, Fig. 3a and $3 \mathrm{~b}(\mathrm{III})$ ), while 1,4-DMP did not influence the angiogenesis (MVD of 6, Fig. 3a and 3b(IV)). The increased proangiogenic activity of 1-MNA was accompanied by a significant increase in 6-keto-PGF1 $\alpha$ plasma concentration (median value of $420.5 \mathrm{pg} / \mathrm{ml}$ vs. $145.2 \mathrm{pg} / \mathrm{ml}$ in a control group of animals). Similarly, elevated 6-keto-PGF1 $\alpha$ concentration was observed in the plasma samples obtained from mice treated with cyclophosphamide $(390.3 \mathrm{pg} / \mathrm{ml})$, while this was not noted in mice treated with 1,4-DMP
(Fig. 3c). In contrast, in all treated groups reduced $\mathrm{TXB}_{2}$ plasma levels were observed (Fig. 3d), while plasma concentrations of vWF and soluble P-selectin were not significantly modified by 1 -MNA or 1,4-DMP as compared to control (Fig. 3e-f).

\section{Anti-cancer activity of 1-MNA and 1,4-DMP in a combined treatment with cyclophosphamide}

Due to the observed effects of 1-MNA and 1,4 DMP on tumor metastasis and angiogenesis, we next decided to investigate the influence of both of the compounds on the anti-cancer efficacy of cyclophosphamide applied in a metronomic dosage regime. The analysis of the primary 4T1 tumor growth kinetics as well as the weight of the tumor mass on the last (29th) day of the experiment indicated that both 1-MNA and 1,4-DMP enhanced the observed anti-tumor activity of cyclophosphamide (median tumor weight in the groups given cyclophosphamide with 1-MNA or 1,4-DMP was estimated as $0.78 \mathrm{~g}$ and $0.61 \mathrm{~g}$, respectively, while the tumor weight in group of mice treated with cyclophosphamide alone was $1.05 \mathrm{~g}$ ), which in the case of the latter resulted in a statistically significant tumor growth inhibition when compared to the control group of animals (tumor weight of $1.51 \mathrm{~g}$, Fig. $4 \mathrm{a}-\mathrm{c}$ ). In contrast, 1-MNA in a combination with cyclophosphamide

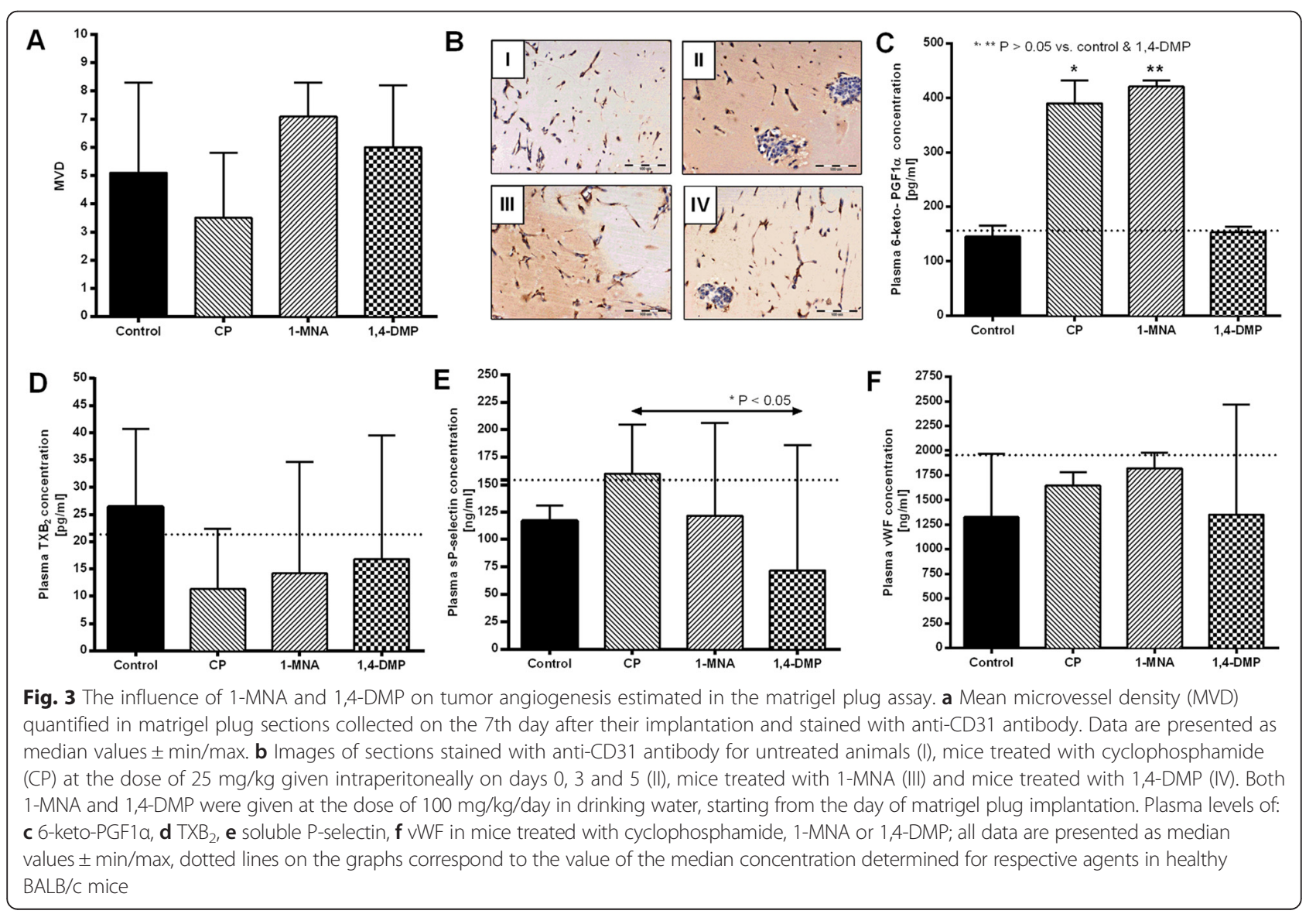



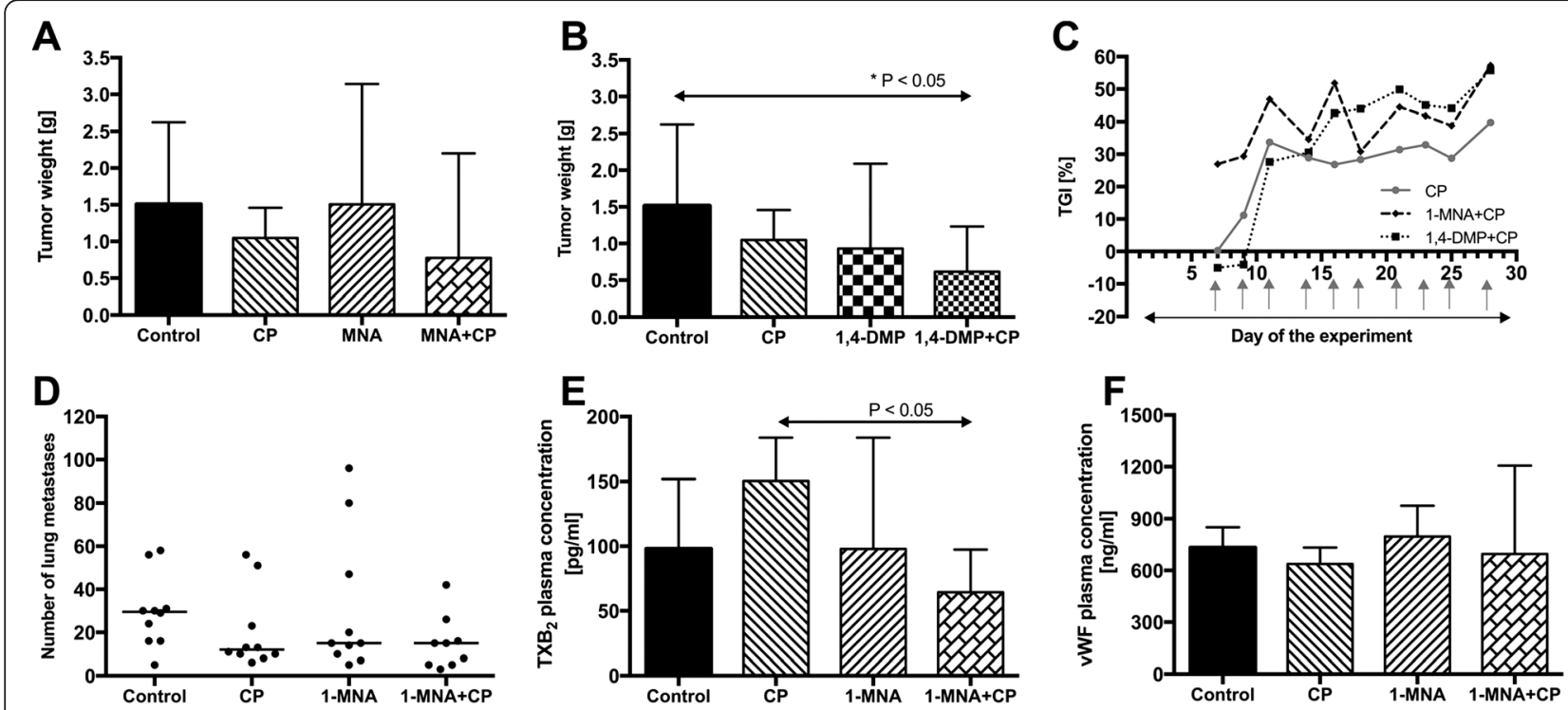

G

H
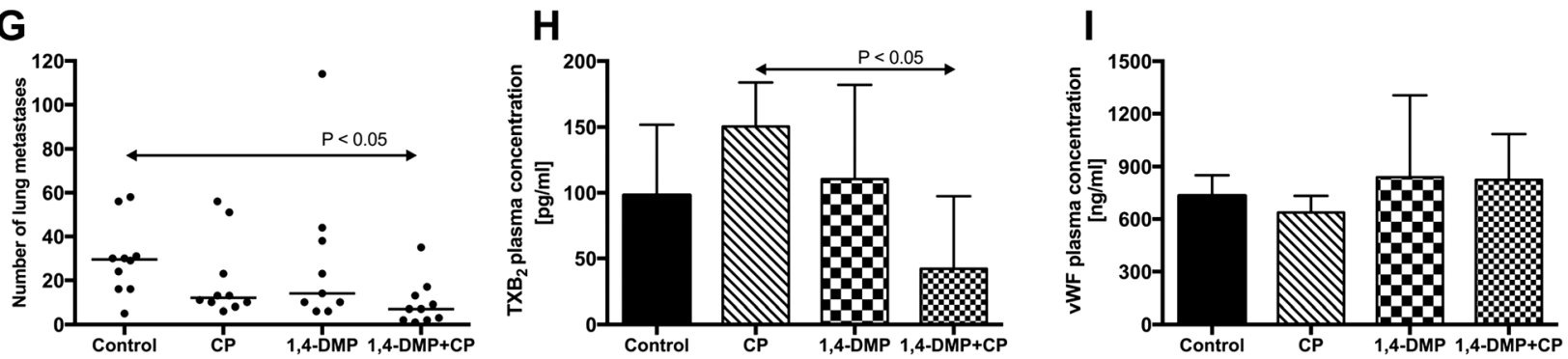

J

(a) (b) (c) (d) (e) (f)

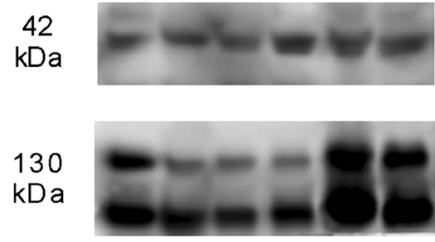

$\beta$-actin

70

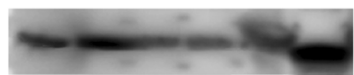

E-cadherin

$\mathrm{N}$-cadherin

K

Fig. 4 Anti-cancer efficacy of a combined treatment regime composed of 1-MNA or 1,4-DMP and cyclophosphamide in the 4T1 cancer model, For ease of interpretation, graphs are presented for the two therapeutic regimes separately. Tumor weight estimated on the $29^{\text {th }}$ day of the experiment for mice treated with a 1-MNA and cyclophosphamide (CP) or $\mathbf{b}$ 1,4-DMP and cyclophosphamide (CP) both presented with relevant controls; data are presented as median values $\pm \mathrm{min} / \mathrm{max}$. c Tumor growth inhibition (TGI) values observed for combined therapeutic regimes presented in reference to TGl of cyclophosphamide alone. In Fig. 4C, days of the drug administrations are indicated with arrows (1-MNA and 1,4-DMP - solid arrow, cyclophosphamide - gray arrows). The number of lung metastases in mice receiving $\mathbf{d}$ 1-MNA and cyclophosphamide (CP) or $\mathbf{g}$

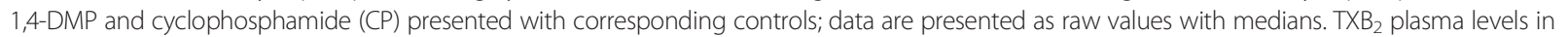
mice receiving e 1-MNA and cyclophosphamide (CP) or $\mathbf{h}$ 1,4-DMP and cyclophosphamide (CP); data are presented as median values \pm min/max. VWF plasma levels in mice receiving $\mathbf{f} 1$-MNA and cyclophosphamide (CP) or i 1,4-DMP and cyclophosphamide (CP); data are presented as median values $\pm \mathrm{min} / \mathrm{max}$. $\mathbf{j}$ The images of bands obtained in Western blot analysis of tissue samples isolated from the animals assigned to treatment with: (a) control, (b) cyclophosphamide (CP), (c) 1-MNA, (d) 1-MNA and cyclophosphamide (CP), (e) 1,4-DMP, (f) 1,4-DMP and cyclophosphamide (CP). k E-cadherin : N-cadherin expression ratios in the samples of tumor tissue collected on the last day of the experiment. The total cellular content of E-cadherin (comprising protein characterized by the molecular weight of 100 and $130 \mathrm{kDa}$ ) and $\mathrm{N}$-cadherin was first normalized to the content of $\beta$-actin and then used to determine E-cadherin to $\mathrm{N}$-cadherin expression ratios that are presented on the graph as median values with $\mathrm{min} / \mathrm{max}$ 
retained the anti-metastatic activity of the cytostatic drug given alone resulting in about a $60 \%$ inhibition of lung metastases formation (12 vs. 29 median number of lung metastases in cyclophosphamide and control group, respectively) (Fig. 4d, 4g). However, when mice were treated with cyclophosphamide given with 1,4DMP, a statistically significant inhibition of lung metastases formation was achieved. The median number of lung metastases (7 lung metastases) was about $80 \%$ lower when compared to the control (29 lung metastases) and about $50 \%$ lower when compared to the group treated with cyclophosphamide given in a single drug therapy (12 lung metastases, Fig. 4g). We also observed that $\mathrm{TXB}_{2}$ plasma level was decreased in those groups with the least number of identified metastases; however, vWF concentration remained at a similar level in all treated animals (Fig. $4 \mathrm{e}-\mathrm{f}$ and $4 \mathrm{~h}-\mathrm{i}$ ).

Interestingly, in tumor tissue isolated from mice treated with 1-MNA alone or in combination with cyclophosphamide, a higher E-cadherin expression that was accompanied with the lower $\mathrm{N}$-cadherin levels was observed. The estimated E-cadherin to $\mathrm{N}$-cadherin ratio in the tissue was more than twice as high as in the control untreated animals. On the other hand, such phenomena did not occur in mice receiving 1,4-DMP either in a single or combined treatment regime (Fig. $4 \mathrm{j}-\mathrm{k}$ ).

\section{Toxicity of the anti-cancer treatment}

Neither of the treatments employed influenced the overall wellbeing of the animals as evidenced by the weight increase observed throughout the whole experiment (Fig. 5a-b). Therapeutic regimes applied in the study did not induce any significant changes in blood morphological parameters that might be attributed to toxic side effects. No cases of treatment-related deaths were recorded.

\section{Discussion}

Anti-thrombotic, anti-inflammatory, and vasoprotective properties of 1-MNA ascribed to its contribution to $\mathrm{PGI}_{2}$ release have been proposed to have therapeutic significance, for example, in atherosclerosis [44]. On the other hand, when studied for its anti-metastatic properties, $\mathrm{PGI}_{2}$, which is the most potent endogenous inhibitor of platelet aggregation, has proven to be an efficient metastasis inhibitor [23, 45]. Stable analogs of $\mathrm{PGI}_{2}$ also displayed anti-cancer activity [38, 40-42]. However, the short lifetime of $\mathrm{PGI}_{2}$ and the side effects of its analogs when given systemically may limit their therapeutic application in oncology. Therefore, a $\mathrm{PGI}_{2}$ releasing agent, such as 1-MNA or its structural analog 1,4-DMP, might become an interesting alternative to the use of $\mathrm{PGI}_{2}$ in the treatment of metastatic cancer. Here, we have demonstrated that in the murine model of metastatic breast cancer 1-MNA and 1,4-DMP both display anti-metastatic activity, particularly during the vascular phase of metastasis and if combined with cyclophosphamide may ensure an efficient strategy for the prevention of mammary gland tumor's metastases formation.

In two separate in vivo studies, both 1-MNA and 1,4DMP inhibited to some degree the spontaneous formation of 4T1 tumor lung metastases while neither of them influenced the growth of 4T1 primary tumors. Moreover, the observed anti-metastatic effect was strongly related to the time of therapy initiation, being more pronounced while 1-MNA and 1,4-DMP were administrated from the time of 4T1 cells orthotopic transplantation. This, in turn, suggests that the activity of both compounds results in the prevention of early 4T1 tumor's metastases formation rather than in any direct influence on established lesions. Such anti-metastatic activity of 1-MNA and 1,4-DMP was further confirmed in the model of experimental metastasis of 4T1-luc2-tdTomato cells that stably express red fluorescent protein and the gene for firefly luciferase. In the
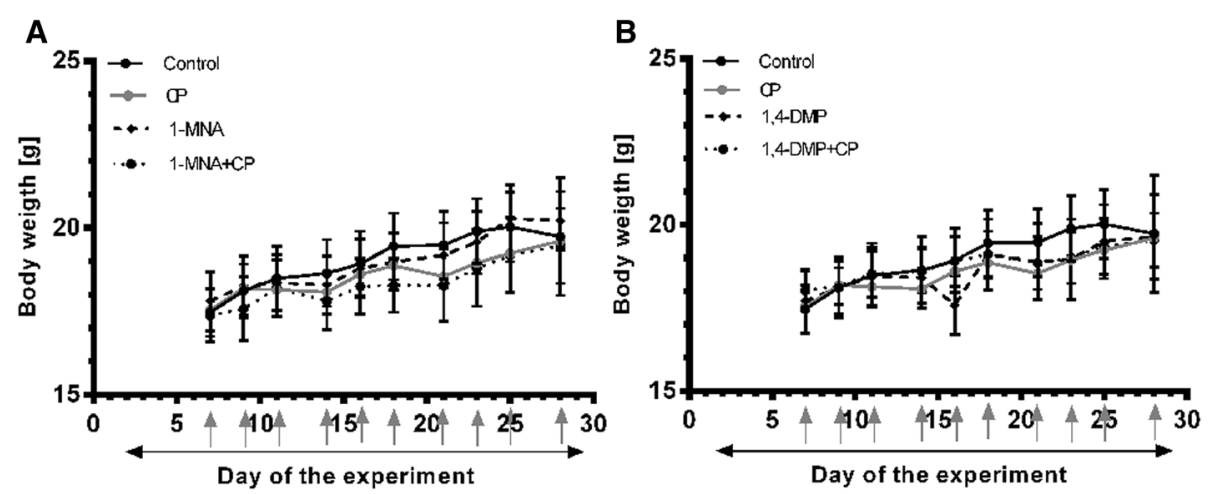

Fig. 5 Body weight of BALB/C mice bearing 4T1 tumors, treated with a 1-MNA and cyclophosphamide (CP) or b 1,4-DMP and cyclophosphamide (CP), both presented with relevant controls. In Fig. 5a-b, days of the drug administrations are indicated with arrows (1-MNA or 1,4-DMP- solid arrow, cyclophosphamide - gray arrows). Data are presented as mean values \pm SD 
study, mice pretreated with either 1-MNA or 1,4-DMP revealed less pronounced metastatic disease characterized by a delayed onset indicating impaired 4T1 cells homing in the lungs. Such results remain in agreement with the previously disclosed anti-metastatic activity of 1-MNA and 1,4-DMP [26] and other published studies suggesting that drugs affecting platelet aggregation or endothelial inflammation might beneficially influence the vascular stage of metastatic dissemination, including adhesion of migrating cancer cells to the vessel wall and subsequent extravasation to the lungs $[46,47]$.

Possible implementation of 1-MNA and 1,4-DMP in the therapy of metastatic breast cancer was further confirmed when both compounds were administrated with cyclophosphamide to $4 \mathrm{~T} 1$ tumor-bearing mice. Interestingly, in the applied tumor model not only did 1MNA and 1,4-DMP inhibit lung metastases formation but also they beneficially influenced the anti-tumor activity of the cytostatic drug. Pronounced tumor growth inhibition in mice receiving the combined treatments was associated with diminished $\mathrm{TXB}_{2}$ plasma levels suggesting potential involvement of platelet-related mechanisms in the anti-cancer activity of both investigated molecules. Moreover, when given with cyclophosphamide, 1,4-DMP further improved the anti-metastatic efficacy of the chemotherapeutic.

Since metastases formation strongly depends on angiogenesis yield [48], we additionally decided to estimate the influence of 1-MNA and 1,4-DMP on vessel formation in either mammary gland tumor mass or matrigel plugs. The results of the studies revealed surprisingly distinct effects of 1-MNA and 1,4-DMP on vasculature development. While 1-MNA stimulated the formation of blood vessels in both angiogenesis models employed, 1,4-DMP did not affect vasculature formation when compared to the control group of animals. Such an observation is not surprising in terms of the proven $\mathrm{PGI}_{2}$ dependent activity of 1-MNA; however, it might indicate that either the $\mathrm{PGI}_{2}$ releasing capacity of $1,4-\mathrm{DMP}$ is lower as compared with 1-MNA, or there is another anti-metastatic mechanism of action that could be featured by this compound. Such an assumption is further supported by the observation that, while both agents seemed to inhibit platelet activity as manifested by the reduced plasma level of $\mathrm{TXB}_{2}$, only 1-MNA induced a profound increase in $\mathrm{PGI}_{2}$ concentration, as reflected in elevated 6-keto-PGF1 $\alpha$ levels. It is known that $\mathrm{PGI}_{2}$ displays pro-angiogenic activity that has been previously shown both in vitro and in vivo, in tumor as well as in ischemia models [49, 50-52]. In fact, Osawa et al. has shown that in tumor endothelial cells (TECs) the expression of the receptor for $\mathrm{PGI}_{2}$ is upregulated, but also that TECs secrete higher levels of $\mathrm{PGI}_{2}$, which in turn stimulates angiogenesis in an autocrine manner [52].
Accordingly, we suspect that observed in our study increased capillary formation, induced in response to the treatment with 1-MNA, resulted from $\mathrm{PGI}_{2}$-releasing activity of the compound. In case of our studies, however, such enhanced tumor angiogenesis did not lead to enhanced tumor growth or metastatic dissemination, but contrarily to lesser number of diagnosed metastases and increased efficacy of the applied chemotherapeutic. Possibly, such effect emerged from the phenomena of tumor vessels normalization that could occur in response to 1-MNA. Such effect is not unparalleled as the relation between vascular permeability and the drug transport efficiency into tumors has been previously described [53]. Also, Li et al. shows that the prevention of VEGF-A induced tumor vasculature leakage increase chemotherapy efficacy and what is even more important the number of distant metastases [54].

It has been previously described that in order to form distant metastasis immobile tumor cells undergo epithelial to mesenchymal transition (EMT), a process in which non-invasive cells loose their epithelial character and develop mesenchymal features to eventually acquire more invasive potential. It has been shown that on the molecular level, EMT is driven by phosphatidylinositol3-kinase/Akt (PI3K/Akt) [55] and extracellular signal regulated kinase 1/2 (ERK1/2) [56] signaling pathways that when activated contributed to an enhanced metastasis [57]. Activation of PI3K/Akt and ERK1/2 in cancer cells eventually leads to the down-regulated E-cadherin and up-regulated $\mathrm{N}$-cadherin expression, among others. Accordingly, decreased E-cadherin cellular content was shown to promote cancer cells motility and invasiveness in vitro and consequently to correlate with worsened survival prognosis in patients [58, 59]. In our study, however, enhanced E-cadherin to $\mathrm{N}$-cadherin expression ratio was observed in mammary gland tumor tissue isolated only from mice treated with 1-MNA or 1-MNA given with cyclophosphamide. It seems probable that 1MNA exerted its anti-metastatic activity on the primary mammary gland tumor level leading to diminished metastatic potential of $4 \mathrm{~T} 1$ cells, while the activity of 1,4-DMP is not directly related to the tumor tissue. Such observation further supports the idea that 1-MNA and 1,4-DMP affect malignant breast cancer progression in different manners.

Besides the undeniable beneficial anti-metastatic activity of the combined treatment comprising either 1MNA or 1,4-DMP and cyclophosphamide, its sustained low toxicity comparable to that revealed by the cytostatic drug given alone is probably the most crucial factor from the clinical point of view. The most undesirable side effect of a treatment implementing anti-platelet drugs is bleeding [60-62]. However, in our study we have not observed any incidence of treatment-related deaths. 
Moreover, the body weight of the treated animals was constantly increasing throughout the study. This might be a consequence of the $\mathrm{PGI}_{2}$ releasing activity of the employed agents. $\mathrm{PGI}_{2}$ has been shown to be a more potent inhibitor of platelet-platelet interactions than an inhibitor of platelet adhesion to damaged endothelium [63]; therefore, it seems to constitute a safe alternative for other non-selective platelet inhibitors. Moreover, the recently described beneficial hepatoprotective activity of 1-MNA and NMMT [64] might suggest its potential preventive activity also against liver damages induced by chemotherapy.

On the other hand, recently published data showing an elevated expression of NMMT in a number of human tumor types and its possible involvement in proliferation, tumorogenic capacity and invasiveness of cancer cells $[2,3,52,65]$ may cause major concerns when considering implementation of 1-MNA and its analogs into the anti-cancer therapeutic regimes. Not only NMMT but also 1-MNA itself was shown to promote cellular growth what in a study of Parsons et al. resulted in the prolonged survival and enhanced proliferation of neurobastoma cells in vitro [66]. However, in our preliminary studies we have established that neither 1-MNA nor 1,4DMP promote the proliferation of breast, prostate or colon cancer cells in vitro, even at the concentrations up to $1000 \mu \mathrm{g} / \mathrm{ml}$. On the contrary, we have observed that while 1-MNA at such concentration did not reveal any influence on the growth of tested cells, 1,4-DMP actually inhibited it in $20 \%$ to almost $50 \%$, depending on the cell line tested (Additional file 1: Table S1). Additionally, as evidenced by the results presented above neither of studied pyridine compounds enhanced the growth of $4 \mathrm{~T} 1$ primary tumors in vivo. Such discrepancy observed between the experimental results regarding the activity of NMMT in tumor cells is not uncommon. For example, while a number of reports indicate the correlation between the NMMT expression and the degree of malignancy [65] other suggest that tumors express high levels of NMMT that promotes early phase of tumorogenicity, but has to be down-regulated to enable metastasis. In fact, these reports attribute NNMT's high expression to the prolonged patients' survival [67-69]. The exact mechanisms involved in the effects of NNMT in cancer cells are not entirely clear, however, it is suspected that they depend on the regulation of the processes based on the availability of NA and methyl groups [70]. Accordingly, down-regulation of NMMT was shown to induce apoptosis in human breast cancer cells [3]. It was reported that 1-MNA might act as NMMT inhibitor [71] what at least in theory could increase the bioavailability of intracellular NA and thus endure the NMMT effect leading to the induced apoptosis and chemosensitization of cancer cells [72, 73]. However, in the light of the results presented here, it seems that a possible direct effect of 1-MNA on 4T1 murine mammary gland cells, if any, is neglectable as it did not result in an enhanced tumorogenesis or chemoresistance development. On the contrary, implementation of 1-MNA and its analogue 1,4-DMP to the treatment of metastatic mammary gland cancer has proven beneficial. Therefore, concerns regarding the use of 1-MNA in the anticancer therapies that may arise on the basis of recently published NMMT activity in cancer cells seem to be unjustified as pro-metastatic activity of NNMT seems to be related to the intracellular methylation status in cancer cells, while exogenous 1-MNA exerts its antiinflammatory and anti-thrombotic properties in circulation and thus indirectly affect cancer cells metastasis.

\section{Conclusions}

The results of the studies presented above indicate that 1MNA and its analog, 1,4-DMP, might be beneficially implemented into the treatment of metastatic breast cancer to ensure a more comprehensive strategy of metastasis control than that based on chemotherapy alone. However, additional studies should be performed to explain their mechanism of action in more detail and to establish whether the observed anti-metastatic activity of both compounds is restricted only to breast cancer or whether it is applicable to a broader range of malignant tumors.

\section{Additional file}

Additional file 1: Figure S1. Body weight of BALB/C Nude mice intravenously inoculated with 4T1-luc2-tdTomato cells treated with 1-MNA or 1.4-DMP in comparison to the control untreated group of animals. Table S1. The influence of 1-MNA and 1,4-DMP on the growth of selected cancer cell lines in vitro. (DOCX 1705 kb)

\section{Abbreviations}

\%BW, \% of body weight; 1,4-DMP, dimethylpyridinium chloride; 1-MNA, 1methylnicotinamide chloride; 6-keto-PGF1a, 6-keto-prostaglandin F1a; AU, arbitrary units; CLO, clopidogrel; COX-2, cyclooxygenase 2; CP, cyclophosphamide; EDTA, ethylenediaminetetraacetic acid; EMT, epithelial to mesenchymal transition; ERK1/2, extracellular signal regulated kinase 1/2; HBSS, Hanks Balanced Salt Solution; IL-4, interleukin 4; NA, nicotinamide; NADH, nicotinamide adenine dinucleotide; NADPH, nicotinamide adenine dinucleotide phosphate; NNMT, nicotinamide N-methyltransferase; PI3K/Akt, phosphatidylinositol-3-kinase/Akt; PS, pyridinium salts; PVDF, polyvinylidene fluoride; ROS, reactive oxygen species; rpm, round per minute; SDS, sodium dodecylosulphate; TCIPA, tumor cell induced platelet; TECs, tumor endothelial cells; TGI, tumor growth inhibition; TNF-a, tumor necrosis factor $a_{\text {; }} T V$, tumor volume; $T_{X B_{2}}$, thromboxane $B_{2}$; VCAM-1, vascular cell adhesion molecule 1; vWF, von Willebrand Factor

\section{Availability of data and material}

All data are presented as calculated mean with SD or median with min- max values, moreover, the data concerning lung metastases count are presented as values (dots) for individual mice.

The data which are not shown in the main body of manuscript are presented in supplementary file.

\section{Authors' contributions}

$A B$, JW and SC conceived and designed the experiments; $A M$ and JG synthetized and provided pyridinium salts; $A B, M S, A N G$ and $M N$ performed the 
experiments; $A B$ analyzed the data and wrote the paper. All authors read and approved the final manuscript.

\section{Competing interest}

The authors declare that they have no competing interests.

\section{Consent for publication}

Not applicable.

\section{Ethics approval and consent to participate}

All animal experiments were performed according to the Interdisciplinary Principles and Guidelines for the Use of Animals in Research, Marketing and Education issued by the New York Academy of Sciences' Ad Hoc Committee on Animal Research and were approved by the 1st Local Committee for Experiments with the Use of Laboratory Animals, Wroclaw, Poland.

\section{Financial support}

This study was supported by the European Union from the resources of the European Regional Development Fund within the Innovative Economy Program (grant coordinated by the JCET-UJ, No POIG.01.01.02-00-069/09) and The National Center for Research and Development under the Polish Strategic Framework Program STRATEGMED (grant coordinated by JCET-UJ No STRATEGMED1/233226/11/NCBR/2015). Publication was supported by Wroclaw Centre of Biotechnology within a Program The Leading National Research Centre (KNOW) for years 2014-2018.

\section{Author details}

${ }^{1}$ Hirszfeld Institute of Immunology and Experimental Therapy, Polish Academy of Sciences, Weigla 12, 53-114 Wroclaw, Poland. ${ }^{2}$ Chair of Pharmacology, Jagiellonian University, Medical College, Grzegórzecka 16, 31-531 Krakow, Poland. ${ }^{3}$ Jagiellonian Center for Experimental Therapeutics (JCET), Jagiellonian University, Bobrzynskiego 14, 30-348 Krakow, Poland. ${ }^{4}$ Lodz University of Technology, Zeromskiego 116, 90-924 Lodz, Poland. ${ }^{5}$ Wroclaw University of Environmental and Life Sciences, Norwida 31, 50-375 Wroclaw, Poland.

\section{Received: 26 April 2016 Accepted: 28 June 2016}

\section{Published online: 13 July 2016}

\section{References}

1. Alston TA, Abeles RH. Substrate specificity of nicotinamide methyltransferase isolated from porcine liver. Arch Biochem Biophys. 1988;260:601-8.

2. Yu T, Wang YT, Chen P, Li YH, Chen YX, Zeng H, Yu AM, Huang M, Bi HC. Effects of nicotinamide N-methyltransferase on PANC-1 cells proliferation, metastatic potential and survival under metabolic stress. Cell Physiol Biochem. 2015;35:710-21.

3. Zhang J, Wang Y, Li G, Yu H, Xie X. Down-regulation of nicotinamide Nmethyltransferase induces apoptosis in human breast cancer cells via the mitochondria-mediated pathway. PLoS One. 2014;9:e89202.

4. Pozzi V, Sartini D, Morganti S, Giuliante R, Di Ruscio G, Santarelli A, Rocchetti R, Rubini C, Tomasetti M, Giannatempo G, et al. RNA-mediated gene silencing of nicotinamide $\mathrm{N}$-methyltransferase is associated with decreased tumorigenicity in human oral carcinoma cells. PLoS One. 2013;8:e71272.

5. Parsons RB, Smith ML, Williams AC, Waring RH, Ramsden DB. Expression of nicotinamide $\mathrm{N}$-methyltransferase (E.C. 2.1.1.1) in the Parkinsonian brain. J Neuropathol Exp Neurol. 2002;61:111-24.

6. Crino A, Schiaffini R, Manfrini S, Mesturino C, Visalli N, Beretta Anguissola G, Suraci C, Pitocco D, Spera S, Corbi S, et al. A randomized trial of nicotinamide and vitamin $\mathrm{E}$ in children with recent onset type 1 diabetes (IMDIAB IX). Eur J Endocrinol. 2004;150:719-24.

7. Chen AC, Martin AJ, Choy B, Fernandez-Penas P, Dalziell RA, McKenzie CA, Scolyer RA, Dhillon HM, Vardy JL, Kricker A, et al. A Phase 3 randomized trial of nicotinamide for skin-cancer chemoprevention. N Engl J Med. 2015;373:1618-26.

8. Maiese $K$, Chong ZZ. Nicotinamide: necessary nutrient emerges as a novel cytoprotectant for the brain. Trends Pharmacol Sci. 2003;24:228-32.

9. Hiromatsu Y, Sato M, Yamada K, Nonaka K. Inhibitory effects of nicotinamide on recombinant human interferon-gamma-induced intercellular adhesion molecule-1 (ICAM-1) and HLA-DR antigen expression on cultured human endothelial cells. Immunol Lett. 1992;31:35-9.

10. Surjana D, Halliday GM, Damian DL. Role of nicotinamide in DNA damage, mutagenesis, and DNA repair. J Nucleic Acids. 2010; 2010:Article ID 157591.
11. Gebicki J, Sysa-Jedrzejowska A, Adamus J, Wozniacka A, Rybak M, Zielonka J. 1-Methylnicotinamide: a potent anti-inflammatory agent of vitamin origin. Pol J Pharmacol. 2003;55:109-12.

12. Wozniacka A, Wieczorkowska M, Gebicki J, Sysa-Jedrzejowska A. Topical application of 1-methylnicotinamide in the treatment of rosacea: a pilot study. Clin Exp Dermatol. 2005;30:632-5.

13. Chlopicki S, Swies J, Mogielnicki A, Buczko W, Bartus M, Lomnicka M, Adamus J, Gebicki J. 1-Methylnicotinamide (MNA), a primary metabolite of nicotinamide, exerts anti-thrombotic activity mediated by a cyclooxygenase-2/prostacyclin pathway. Br J Pharmacol. 2007;152:230-9.

14. Mogielnicki A, Kramkowski K, Pietrzak L, Buczko W. N-methylnicotinamide inhibits arterial thrombosis in hypertensive rats. J Physiol Pharmacol. 2007:58:515-27.

15. Bryniarski K, Biedron R, Jakubowski A, Chlopicki S, Marcinkiewicz J. Antiinflammatory effect of 1-methylnicotinamide in contact hypersensitivity to oxazolone in mice; involvement of prostacyclin. Eur J Pharmacol. 2008:578:332-8.

16. Brzozowski T, Konturek PC, Chlopicki S, Sliwowski Z, Pawlik M, PtakBelowska A, Kwiecien S, Drozdowicz D, Pajdo R, Slonimska E, et al. Therapeutic potential of 1-methylnicotinamide against acute gastric lesions induced by stress: role of endogenous prostacyclin and sensory nerves. J Pharmacol Exp Ther. 2008;326:105-16.

17. Biedron R, Ciszek M, Tokarczyk M, Bobek M, Kurnyta M, Slominska EM, Smolenski RT, Marcinkiewicz J. 1-Methylnicotinamide and nicotinamide: two related anti-inflammatory agents that differentially affect the functions of activated macrophages. Arch Immunol Ther Exp (Warsz). 2008;56:127-34.

18. Mogielnicki A, Kramkowski K, Hermanowicz JM, Buczko W. Nmethylnicotinamide failed to induce endothelial prostacyclin release in perfused rat hindquarters. Pharmacol Rep. 2008;60:1025-9.

19. Sternak M, Khomich TI, Jakubowski A, Szafarz M, Szczepanski W, Bialas M, Stojak M, Szymura-Oleksiak J, Chlopicki S. Nicotinamide N-methyltransferase (NNMT) and 1-methylnicotinamide (MNA) in experimental hepatitis induced by concanavalin A in the mouse. Pharmacol Rep. 2010;62:483-93.

20. Jakubowski A, Sternak M, Jablonski K, Ciszek-Lenda M, Marcinkiewicz J, Chlopicki S. 1-Methylnicotinamide protects against liver injury induced by concanavalin A via a prostacyclin-dependent mechanism: A possible involvement of IL-4 and TNF-alpha. Int Immunopharmacol. 2016;31:98-104.

21. Bartus M, Lomnicka M, Kostogrys RB, Kazmierczak P, Watala C, Slominska EM, Smolenski RT, Pisulewski PM, Adamus J, Gebicki J, Chlopicki S. 1-Methylnicotinamide (MNA) prevents endothelial dysfunction in hypertriglyceridemic and diabetic rats. Pharmacol Rep. 2008;60:127-38.

22. Domagala TB, Szeffler A, Dobrucki LW, Dropinski J, Polanski S, LeszczynskaWiloch M, Kotula-Horowitz K, Wojciechowski J, Wojnowski L, Szczeklik A, Kalinowski L. Nitric oxide production and endothelium-dependent vasorelaxation ameliorated by N1-methylnicotinamide in human blood vessels. Hypertension. 2012;59:825-32.

23. Honn KV. Inhibition of tumor cell metastasis by modulation of the vascular prostacyclin/thromboxane A2 system. Clin Exp Metastasis. 1983;1:103-14.

24. Honn KV, Cicone B, Skoff A. Prostacyclin: a potent antimetastatic agent. Science. 1981;212(4500):1270-2.

25. Wieczorkowska M, Szajerski P, Michalski R, Adamus J, Marciniak A, Gebicki J, Ciesielska E, Szmigiero L, Lech-Maranda E, Szmigielska-Kaplon A, Robak T. Cytotoxic activity of the selected pyridinium salts against murine leukemia L1210. Pharmacol Rep. 2007;59:216-23.

26. Gebicki J, Marcinek A, Chlopicki S. Use of quaternary pyridinium salts for inhibiting cancer metastases. European patent EP 2211 858, 2015.23.

27. Kalaska B, Piotrowski L, Leszczynska A, Michalowski B, Kramkowski K, Kaminski T, Adamus J, Marcinek A, Gebicki J, Mogielnicki A, Buczko W. Antithrombotic effects of pyridinium compounds formed from trigonelline upon coffee roasting. J Agric Food Chem. 2014;62:2853-60.

28. Blazejczyk A, Papiernik D, Porshneva K, Sadowska J, Wietrzyk J. Endothelium and cancer metastasis: Perspectives for antimetastatic therapy. Pharmacol Rep. 2015;67:711-8.

29. Khorana AA. Cancer-associated thrombosis: updates and controversies. Hematology Am Soc Hematol Educ Program. 2012;2012:626-30.

30. Placke T, Orgel M, Schaller M, Jung G, Rammensee HG, Kopp HG, Salih HR. Platelet-derived MHC class I confers a pseudonormal phenotype to cancer cells that subverts the antitumor reactivity of natural killer immune cells. Cancer Res. 2012;72:440-8.

31. Palumbo JS, Talmage KE, Massari JV, La Jeunesse CM, Flick MJ, Kombrinck KW, Jirouskova M, Degen JL. Platelets and fibrin(ogen) increase metastatic 
potential by impeding natural killer cell-mediated elimination of tumor cells. Blood. 2005;105:178-85.

32. Bendas G, Borsig L. Cancer cell adhesion and metastasis: selectins, integrins, and the inhibitory potential of heparins. Int J Cell Biol. 2012;2012:676731.

33. Kispert SE, Marentette JO, McHowat J. Enhanced breast cancer cell adherence to the lung endothelium via PAF acetylhydrolase inhibition: a potential mechanism for enhanced metastasis in smokers. Am J Physiol Cell Physiol. 2014;307:C951-6.

34. Gebremeskel S, LeVatte T, Liwski RS, Johnston B, Bezuhly M. The reversible P2Y12 inhibitor ticagrelor inhibits metastasis and improves survival in mouse models of cancer. Int J Cancer. 2015;136:234-40.

35. Toliopoulos IK, Simos YV, Daskalou TA, Verginadis II, Evangelou AM, Karkabounas SC. Inhibition of platelet aggregation and immunomodulation of NK lymphocytes by administration of ascorbic acid. Indian J Exp Biol. 2011;49:904-8.

36. Algra AM, Rothwell PM. Effects of regular aspirin on long-term cancer incidence and metastasis: a systematic comparison of evidence from observational studies versus randomised trials. Lancet Oncol. 2012;13:518-27.

37. Mezouar S, Darbousset R, Dignat-George F, Panicot-Dubois L, Dubois C. Inhibition of platelet activation prevents the P-selectin and integrindependent accumulation of cancer cell microparticles and reduces tumor growth and metastasis in vivo. Int J Cancer. 2015;136:462-75.

38. Yoshida N, Yoshikawa T, Nakagawa S, Sakamoto K, Nakamura Y, Naito Y, Kondo M. Effect of shear stress and a stable prostaglandin 12 analogue on adhesive interactions of colon cancer cells and endothelial cells. Clin Exp Immunol. 1999:117:430-4.

39. Daneker GW, Lund SA, Caughman SW, Staley CA, Wood WC. Anti-metastatic prostacyclins inhibit the adhesion of colon carcinoma to endothelial cells by blocking E-selectin expression. Clin Exp Metastasis. 1996;14:230-8.

40. Schirner M, Schneider MR. Cicaprost inhibits metastases of animal tumors. Prostaglandins. 1991;42:451-61.

41. Schirner M, Schneider MR. The prostacyclin analogue cicaprost inhibits metastasis of tumours of R 3327 MAT Lu prostate carcinoma and SMT 2A mammary carcinoma. J Cancer Res Clin Oncol. 1992;1 18:497-501.

42. Sava G, Perissin L, Zorzet S, Piccini P, Giraldi T. Antimetastatic action of the prostacyclin analog iloprost in the mouse. Clin Exp Metastasis. 1989;7:671-8.

43. Milczarek M, Filip-Psurska B, Swietnicki W, Kutner A, Wietrzyk J. Vitamin D analogs combined with 5-fluorouracil in human HT-29 colon cancer treatment. Oncol Rep. 2014:32:491-504.

44. Mateuszuk L, Jasztal A, Maslak E, Gasior-Glogowska M, Baranska M, Sitek B, Kostogrys R, Zakrzewska A, Kij A, Walczak M, Chlopicki S. Antiatherosclerotic Effects of 1-Methylnicotinamide in Apolipoprotein E/Low-Density Lipoprotein Receptor-Deficient Mice: A Comparison with Nicotinic Acid. J Pharmacol Exp Ther. 2016;356:514-24.

45. Tzanakakis GN, Agarwal KC, Vezeridis MP. Inhibition of hepatic metastasis from a human pancreatic adenocarcinoma (RWP-2) in the nude mouse by prostacyclin, forskolin, and ketoconazole. Cancer. 1990;65:446-51.

46. Nojiri T, Hosoda H, Tokudome T, Miura K, Ishikane S, Otani K, Kishimoto I, Shintani $Y$, Inoue M, Kimura T, et al. Atrial natriuretic peptide prevents cancer metastasis through vascular endothelial cells. Proc Natl Acad Sci U S A. 2015;112:4086-91.

47. Yoshitomi Y, Nakanishi H, Kusano Y, Munesue S, Oguri K, Tatematsu M, Yamashina I, Okayama M. Inhibition of experimental lung metastases of Lewis lung carcinoma cells by chemically modified heparin with reduced anticoagulant activity. Cancer Lett. 2004;207:165-74.

48. Weidner N, Semple JP, Welch WR, Folkman J. Tumor angiogenesis and metastasis-correlation in invasive breast carcinoma. N Engl J Med. 1991;324:1-8.

49. Aburakawa Y, Kawabe J, Okada M, Yamauchi A, Asanome A, Kabara M, Matsuki M, Takehara N, Nakagawa N, Okumura S, et al. Prostacyclin stimulated integrin-dependent angiogenic effects of endothelial progenitor cells and mediated potent circulation recovery in ischemic hind limb model. Circ J. 2013;77:1053-62.

50. Limjeerajarus CN, Osathanon T, Manokawinchoke J, Pavasant P. lloprost upregulates vascular endothelial growth factor expression in human dental pulp cells in vitro and enhances pulpal blood flow in vivo. J Endod. 2014:40:925-30.

51. Peshavariya HM, Liu GS, Chang CW, Jiang F, Chan EC, Dusting GJ. Prostacyclin signaling boosts NADPH oxidase 4 in the endothelium promoting cytoprotection and angiogenesis. Antioxid Redox Signal. 2014;20:2710-25.

52. Osawa T, Ohga N, Hida Y, Kitayama K, Akiyama K, Onodera Y, Fujie M, Shinohara N, Shindoh M, Nonomura K, Hida K. Prostacyclin receptor in tumor endothelial cells promotes angiogenesis in an autocrine manner. Cancer Sci. 2012;103:1038-44.
53. Chauhan VP, Stylianopoulos T, Martin JD, Popović Z, Chen O, Kamoun WS, Bawendi MG, Fukumura D, Jain RK. Normalization of tumour blood vessels improves the delivery of nanomedicines in a size-dependent manner. Nat Nanotechnol. 2012;7:383-8.

54. Li X, Padhan N, Sjostrom EO, Roche FP, Testini C, Honkura N, Sainz-Jaspeado M, Gordon E, Bentley K, Philippides A, et al. VEGFR2 pY949 signalling regulates adherens junction integrity and metastatic spread. Nat Commun. 2016;7:11017.

55. Larue L, Bellacosa A. Epithelial-mesenchymal transition in development and cancer: role of phosphatidylinositol 3' kinase/AKT pathways. Oncogene. 2005;24:7443-54.

56. Buonato JM, Lazzara MJ. ERK1/2 blockade prevents epithelial-mesenchymal transition in lung cancer cells and promotes their sensitivity to EGFR inhibition. Cancer Res. 2014;74:309-19.

57. Shi M, Chen D, Yang D, Liu XY. CCL21-CCR7 promotes the lymph node metastasis of esophageal squamous cell carcinoma by up-regulating MUC1. J Exp Clin Cancer Res. 2015;34:149.

58. Fei F, Zhang D, Yang Z, Wang S, Wang X, Wu Z, Wu Q, Zhang S. The number of polyploid giant cancer cells and epithelial-mesenchymal transition-related proteins are associated with invasion and metastasis in human breast cancer. J Exp Clin Cancer Res. 2015;34:158.

59. Xu C, Hua F, Chen Y, Huang H, Ye W, Yu Y, Shen Z. MTA1 promotes metastasis of MPM via suppression of E-cadherin. J Exp Clin Cancer Res. 2015;34:151.

60. Masclee GM, Valkhoff VE, Coloma PM, de Ridder M, Romio S, Schuemie MJ, Herings R, Gini R, Mazzaglia G, Picelli G, et al. Risk of upper gastrointestinal bleeding from different drug combinations. Gastroenterology. 2014;147:784-92.

61. Naruse Y, Sato A, Hoshi T, Takeyasu N, Kakefuda Y, Ishibashi M, Misaki M, Abe D, Aonuma K. Triple antithrombotic therapy is the independent predictor for the occurrence of major bleeding complications: analysis of percent time in therapeutic range. Circ Cardiovasc Interv. 2013;6:444-51.

62. Yasuda H, Matsuo Y, Sato Y, Ozawa S-i, Ishigooka S, Yamashita M, Yamamoto $\mathrm{H}$, Itoh F. Treatment and prevention of gastrointestinal bleeding in patients receiving antiplatelet therapy. World J Crit Care Med. 2015;4:40-6.

63. Majed BH, Khalil RA. Molecular mechanisms regulating the vascular prostacyclin pathways and their adaptation during pregnancy and in the newborn. Pharmacol Rev. 2012;64:540-82.

64. Hong S, Moreno-Navarrete JM, Wei X, Kikukawa Y, Tzameli I, Prasad D, Lee Y, Asara JM, Fernandez-Real JM, Maratos-Flier E, Pissios P. Nicotinamide Nmethyltransferase regulates hepatic nutrient metabolism through Sirt1 protein stabilization. Nat Med. 2015;21:887-94.

65. Chen C, Wang X, Huang X, Yong H, Shen J, Tang Q, Zhu J, Ni J, Feng Z. Nicotinamide $\mathrm{N}$-methyltransferase: a potential biomarker for worse prognosis in gastric carcinoma. Am J Cancer Res. 2016;6:649-63.

66. Parsons RB, Aravindan S, Kadampeswaran A, Evans EA, Sandhu KK, Levy ER, Thomas MG, Austen BM, Ramsden DB. The expression of nicotinamide Nmethyltransferase increases ATP synthesis and protects SH-SY5Y neuroblastoma cells against the toxicity of Complex I inhibitors. Biochem J. 2011;436:145-55.

67. Bi HC, Pan YZ, Qiu JX, Krausz KW, Li F, Johnson CH, Jiang CT, Gonzalez FJ, Yu AM. N-methylnicotinamide and nicotinamide $\mathrm{N}$-methyltransferase are associated with microRNA-1291-altered pancreatic carcinoma cell metabolome and suppressed tumorigenesis. Carcinogenesis. 2014;35:2264-72.

68. Sartini D, Santarelli A, Rossi V, Goteri G, Rubini C, Ciavarella D, Lo Muzio L, Emanuelli M. Nicotinamide N-methyltransferase upregulation inversely correlates with lymph node metastasis in oral squamous cell carcinoma. Mol Med. 2007;13:415-21.

69. Zhou W, Gui M, Zhu M, Long Z, Huang L, Zhou J, He L, Zhong K. Nicotinamide -methyltransferase is overexpressed in prostate cancer and correlates with prolonged progression-free and overall survival times. Oncol Lett. 2014:8:1175-80.

70. Ulanovskaya OA, Zuhl AM, Cravatt BF. NNMT promotes epigenetic remodeling in cancer by creating a metabolic methylation sink. Nat Chem Biol. 2013:9:300-6.

71. Aksoy S, Szumlanski CL, Weinshilboum RM. Human liver nicotinamide Nmethyltransferase. CDNA cloning, expression, and biochemical characterization. J Biol Chem. 1994;269:14835-40.

72. Wang T, Cui H, Ma N, Jiang Y. Nicotinamide-mediated inhibition of SIRT1 deacetylase is associated with the viability of cancer cells exposed to antitumor agents and apoptosis. Oncol Lett. 2013;6:600-4.

73. Audrito V, Vaisitti T, Rossi D, Gottardi D, D'Arena G, Laurenti L, Gaidano G, Malavasi F, Deaglio S. Nicotinamide blocks proliferation and induces apoptosis of chronic lymphocytic leukemia cells through activation of the p53/miR-34a/SIRT1 tumor suppressor network. Cancer Res. 2011;71:4473-83. 